\title{
ASO Author Reflections: Revival of the In-Situ Hypothermic Perfusion? The Role of Complex Liver Surgery in the Modern Era
}

\author{
Mohammad H. Fard-Aghaie, MD ${ }^{1}$, and Karl J. Oldhafer, MD $^{1}$ \\ Department of General and Abdominal Surgery, Asklepios Klinik Barmbek, Hamburg, Germany
}

\section{PAST}

Time has passed since Fortner described his technique "In-situ hypothermic perfusion." At that time, tumors infiltrating the hepatic venous confluence were irresectable. ${ }^{1}$ His technique evolved to the ex situ procedure, described by Pichlmayer, and the Ante-Situm procedure, described by Hannoun. ${ }^{2,3}$ Due to their complexity, these techniques are only applied in few centers. Additionally, the development of interventional therapies has questioned the role of these complex surgeries. Are these techniques still necessary in modern liver surgery?

\section{PRESENT}

Although the in situ hypothermic perfusion is an old technique, perioperative management evolved and made complex liver surgery safer. Therefore, if the current technology and management are combined, complex liver surgery can be safely applied.

\section{FUTURE}

In the era of highly potent chemotherapies (especially in colorectal liver metastases) and interventional therapies, complex liver surgery, such as in situ hypothermic perfusion, needs to be applied with caution. ${ }^{4}$ However, in some patients resection might be the last choice. Therefore, in the future, hepatobiliary surgeons should be able to discuss all available options with the patient. ${ }^{5}$

DISCLOSURE The author has no conflicts of interest to disclose.

\section{REFERENCES}

1. Fortner JG, et al. Major hepatic resection using vascular isolation and hypothermic perfusion. Ann Surg 1974;180(4):644-52.

2. Pichlmayr R, et al. Ex situ operation on the liver. A new possibility in liver surgery. Langenbecks Arch Chir 1988;373(2):122-6.

3. Hannoun L, et al. Ex-situ in vivo liver surgery. Lancet 1991;337(8757):1616-7.

4. Azoulay D, et al. Complex liver resection using standard total vascular exclusion, venovenous bypass, and in situ hypothermic portal perfusion: an audit of 77 consecutive cases. Ann Surg 2015;262(1):93-104.

5. Oldhafer KJ, Stavrou GA, Wagner KC, et al. Liver resection with in situ hypothermic perfusion. Ann Surg Oncol 2019;26:1859.

Publisher's Note Springer Nature remains neutral with regard to jurisdictional claims in published maps and institutional affiliations.

ASO Author Reflections is a brief invited commentary on the article, "Liver Resection with In Situ Hypothermic Perfusion: An Old but Effective Method." Ann Surg Oncol. 2019;26:1859.

(C) Society of Surgical Oncology 2019

First Received: 20 May 2019;

Published Online: 26 June 2019

M. H. Fard-Aghaie, MD

e-mail: m.fard@asklepios.com 